\title{
Contaminating reactivity of a monoclonal CCAAT/Enhancer Binding Protein $\beta$ antibody in differentiating myoblasts
}

\author{
Hamood AlSudais ${ }^{1}$ and Nadine Wiper-Bergeron ${ }^{2^{*}}$ (1)
}

\begin{abstract}
Objective: CCAAT/Enhancer Binding proteins (C/EBPs) are transcription factors involved in the regulation of a variety of cellular processes. We used the Abcam Recombinant Anti-C/EBP beta antibody (E299) to detect C/EBP $\beta$ expression during myogenesis. Though the antibody is monoclonal, and the immunogen used is highly specific to $C / E B P \beta$, we identified an intense band at $23 \mathrm{kDa}$ on western blot that did not correspond to any of the known isoforms of $C / E B P \beta$, or family members predicted to cross-react. Absent in myoblast cells overexpressing C/EBP $\beta$, the band was present when C/EBP $\beta$ was knocked down, confirming specificity for a protein other than C/EBP $\beta$. The objective of this work was to identify the contaminating reactivity.

Results: We performed immunoprecipitation followed by mass spectrometry to identified myosin light chain 4 (MYL4) as the unknown band, suggesting that the Abcam monoclonal antibody directed against C/EBP $\beta$ is not pure, but contains a contaminating antibody against MYL4. Caution should be used when working in cells lines that express MYL4 to not confound the detection of MYL4 with that of C/EBP $\beta$ isoforms.
\end{abstract}

Keywords: Myogenesis, C/EBP $\beta$, Myoblast, Antibody cross-reactivity, MYL4

\section{Introduction}

Antibody specificity is key to rigorous and reproducible research findings. Antibodies can be polyclonal, meaning a mixture of antibodies secreted by several clones of $B$ cells in response to an antigen, or monoclonal, where a single clone of B cells is used to produce an antibody with an affinity to a defined epitope. Monoclonal antibodies are known to have high specificity and less background noise, as well as consistency from batch to batch.

Monoclonal antibodies are produced by inoculating mice with a peptide antigen to elicit an immune response. The recovered splenocytes are fused to myeloma cells and then expanded into individual clones to generate hybridomas [1]. All hybridomas thus have a single specificity dictated by the epitope and any cross-reactivity is

\footnotetext{
*Correspondence: Nadine.WiperBergeron@uottawa.ca

${ }^{2}$ Department of Cellular and Molecular Medicine, Faculty of Medicine, University of Ottawa, 451 Smyth Road, Rm 2539, K1H 8M5, Ottawa, ON, Canada

Full list of author information is available at the end of the article
}

due to similarity between the inoculating sequence and other proteins [2].

Our laboratory is interested in the regulation of myogenesis by the bzip transcription factor CCAAT/ Enhancer Binding Protein beta $(C / E B P \beta) . C / E B P \beta$ is widely expressed and has been shown to play a role in cell differentiation, apoptosis and inflammation [3, 4]. Cebpb is an intronless gene that produces three protein isoforms from a single mRNA though leaky ribosomal scanning: Liver-enriched Activator protein* (LAP*), LAP, and LIP (Liver-enriched inhibitory protein) [4-6].

To detect the expression of all protein isoforms of $\mathrm{C} /$ $\mathrm{EBP} \beta$, antibodies specific to the $\mathrm{C}$-terminus are required. Beginning in 2014, we began validation experiments for a monoclonal anti-C/EBP $\beta$ antibody (E299, Abcam, ab32358). Our research focuses on muscle stem cells, called satellite cells, that confer regenerative potential to skeletal muscle [7, 8]. In response to muscle injury, satellite cells become activated, differentiate and fuse to form myofibers that express contractile proteins [8]. In healthy 
muscle, satellite cells express C/EBP $\beta$ which inhibits myogenic differentiation $[9,10]$. Upon induction of differentiation, C/EBP $\beta$ expression dramatically decreases, allowing differentiation to proceed [9-11]. We report that the anti-C/EBP $\beta$ antibody also detects myosin light chain 4 (MYL4) in differentiating myoblasts and in other cell lines. Because MYL4 protein is detected at approximately $23 \mathrm{kDa}$, this contaminating band can be confused with the LIP isoform of C/EBP $\beta$; therefore, this anti-C/ EBP $\beta$ should be used with caution in tissues that express MYL4, including skeletal and cardiac muscle.

\section{Main text Methods \\ Cell culture}

C2C12 myoblasts (ATCC) were grown in Dulbecco's Modified Eagle medium (DMEM) with $10 \%$ fetal bovine serum (FBS) (GM, growth media) and differentiation was induced by switching confluent cells to DMEM with $2 \%$ horse serum (HS). Mouse primary myoblasts were isolated and cultured as previously described [9] and maintained on Matrigel-coated plates in DMEM (Wisent) with 20\% FBS (Wisent), 10\% HS (Sigma), $10 \mathrm{ng} / \mathrm{ml}$ basic fibroblast growth factor and $2 \mathrm{ng} / \mathrm{ml}$ hepatocyte growth factor (Peprotech). To induce differentiation, confluent cultures were switched to differentiation media (DMEM, $2 \% \mathrm{FBS}, 10 \% \mathrm{HS}$ ). In vitro Cre recombinase (Cre) fused to a mutant estrogen ligand-binding domain $\left(E^{\mathrm{tm}}\right)$ $\left(C r e E R^{\mathrm{tm}}\right)$ activity was induced in primary myoblasts $\left(\mathrm{Cebpb}^{\mathrm{f} / \mathrm{fl}} \mathrm{Pax}^{\mathrm{wt} / \mathrm{wt}}\right.$ (WT) and Cebpb ${ }^{\mathrm{f} / \mathrm{fl}} \mathrm{Pax} 7^{\mathrm{CreER} / \mathrm{wt}}$ (conditional knockout, cKO) with $2 \mu \mathrm{M}$ 4-OH tamoxifen (Sigma) for $48 \mathrm{~h}$. Retroviruses were generated in Phoenix Ampho packaging cells (ATCC) and retroviral transductions performed as previously described [9].

\section{Western analysis}

Whole cell extracts from primary myoblasts or $\mathrm{C} 2 \mathrm{C} 12$ cells were resolved on a 15\% SDS-PAGE gel, transferred to Polyvinylidene difluoride (PVDF) membrane (Bio$\mathrm{Rad})$, and probed with the following primary antibodies: C/EBP $\beta$ (E299, ab32358, Abcam), MYL (F5, sc-365243, Santa Cruz), MYL12A/B (A-10, sc-376606, Santa Cruz), MYL4 (ab231800, Abcam) and Cyclophilin B (ab16045, Abcam). The ChemiDoc ${ }^{\mathrm{TM}}$ MP system (Bio-Rad) was used to detect chemiluminescence.

\section{Immunoprecipitation}

Differentiated $\mathrm{C} 2 \mathrm{C} 12$ myoblasts were collected in lysis buffer $(50 \mathrm{mM}$ Tris-base pH 7.5, $150 \mathrm{mM} \mathrm{NaCl}, 1 \%$ NP-40 and $1 \mathrm{X}$ protease inhibitor) and agitated for $20 \mathrm{~min}$ at $4{ }^{\circ} \mathrm{C}$. Samples were spun for $10 \mathrm{~min}$ at $4000 \mathrm{~g}$ and supernatants were collected and precleared with magnetic protein-G-dynabeads (Invitrogen). Approximately
$1 \mathrm{mg}$ of protein was incubated with $4 \mu \mathrm{g}$ of anti-C/EBP $\beta$ (ab32358) or non-specific IgG (Invitrogen) for $3 \mathrm{~h}$ at $4{ }^{\circ} \mathrm{C}$, while $3 \%$ of protein was kept for loading input. Immunoprecipitates were captured using Protein-G-beads and extensively washed in $50 \mathrm{mM}$ Tris-base $\mathrm{pH} 7.5,150 \mathrm{mM}$ $\mathrm{NaCl}$ and $1 \% \mathrm{NP}-40$ and pellets were resuspended in lysis buffer with 5X SDS loading buffer and resolved on a 15\% SDS gel for proteomics analysis.

\section{Protein Identification by LC-MS/MS}

Proteomics analysis was performed at the Ottawa Hospital Research Institute Proteomics Core Facility. Proteins were digested in-gel using trypsin (Promega) according to the method of Shevchenko [13]. Peptide extracts were concentrated by Vacufuge (Eppendorf) and LC-MS/MS was performed using a Dionex Ultimate 3000 RLSC nano HPLC (Thermo Scientific) and Orbitrap Fusion Lumos mass spectrometer (Thermo Scientific). MASCOT software version 2.6 (Matrix Science, UK) was used to infer peptide and protein identities from the mass spectra. The observed spectra were matched against mouse sequences from SwissProt (version 2016-09) and against an inhouse database of common contaminants. The results were exported to Scaffold (Proteome Software, USA).

\section{Results \\ Anti-C/EBP $\beta$ (E299) antibody from Abcam (ab32358) detects three $C / E B P \beta$ isoforms in myoblasts}

To validate the Abcam anti-C/EBP $\beta$ antibody in myogenic cultures, we performed western blot of $\mathrm{C} 2 \mathrm{C} 12$ myoblasts that were retrovirally transduced to express the LAP isoform (C/EBP $\beta$-LAP), the LIP (C/EBP $\beta$-LIP) isoform, all $C / E B P \beta$ isoforms $(\beta)$ or with empty virus (pLXSN). The antibody successfully detected endogenous LAP, and the LAP $(\sim 36 \mathrm{kDa})$ and LIP $(\sim 17 \mathrm{kDa})$ isoforms in $\mathrm{C} / \mathrm{EBP} \beta$-overexpressing cells (Fig. 1a).

\section{Anti-C/EBP $\beta$ antibody (ab32358) detects a non-specific band in differentiating myoblasts}

We next evaluated the ability of anti-C/EBP $\beta$ to detect endogenous $\mathrm{C} / \mathrm{EBP} \beta$ expression in proliferating and differentiating myoblasts. $C / E B P \beta$ expression is highest in proliferating myoblasts, and is rapidly downregulated after induction to differentiate in low serum conditions. C2C12 myoblasts were expanded in growth medium (GM) for $48 \mathrm{~h}$ then differentiated in differentiation medium (DM) for $96 \mathrm{~h}$. Consistent with our previous findings [9-11], C/EBP $\beta$-LAP is the most predominantly expressed isoform in myoblasts and its expression decreased $24 \mathrm{~h}$ after induction to differentiate (Fig. 1b). However, beginning at $48 \mathrm{~h}$ of differentiation, a strong band, far more intense that the signal for $C / E B P \beta$, was detected at $\sim 23 \mathrm{kDa}$ and this band was not detected in 

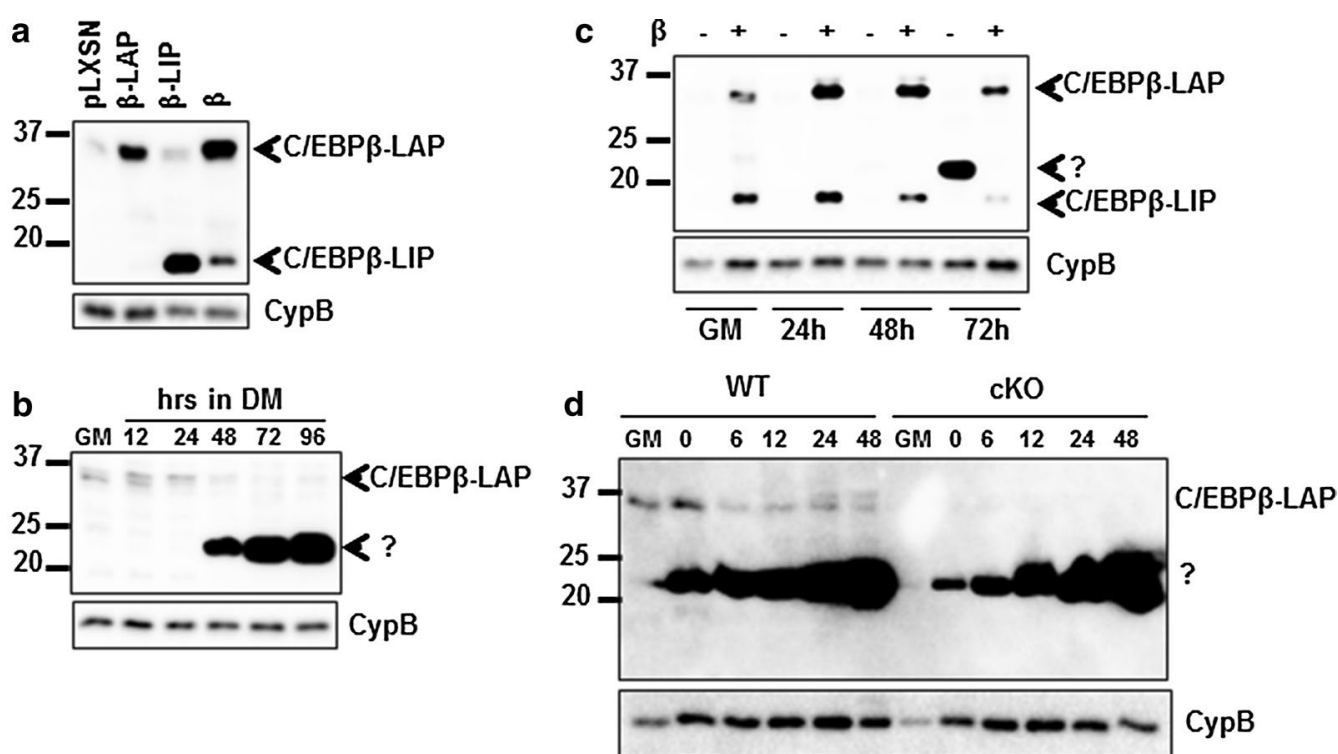

Fig. 1 Anti-C/EBP $\beta$ antibody E299 detects a $\sim 23 \mathrm{kDa}$ band in differentiating myoblasts. a $C / E B P \beta$ protein expression in proliferating $C 2 C 12$ myoblasts that were retrovirally transduced to express the LAP isoform of C/EBP $\beta$ ( $\beta$-LAP), the LIP isoform ( $\beta$-LIP), the full length $C / E B P \beta$ ( $\beta$ ) or with empty virus (pLXSN). $\mathbf{b}$ C/EBP $\beta$ protein expression in proliferating (growth medium, GM) or differentiating (differentiation medium, DM, 12-96 h) C2C12 myoblasts. Migration of the unexpected band is indicated by "?". c C/EBP $\beta$ protein expression in proliferating (GM) or differentiating (24-72 h) $\mathrm{C} 2 \mathrm{C} 12$ myoblasts that were retrovirally transduced to express $\mathrm{C} / \mathrm{EBP} \beta(\beta)$ or with empty virus ( $\mathrm{PLXSN}$ ). $\mathbf{d} \mathrm{C} / \mathrm{EBP} \beta$ protein expression in proliferating (GM) or differentiating (0-48 h) primary myoblasts isolated from Cebpb $b^{\mathrm{f} / \mathrm{fl}} \mathrm{Pax} 7^{+/+}$(WT) and Cebpb $b^{\mathrm{f} / \mathrm{f}} \mathrm{Pax} 7^{\mathrm{CreER} /+}$ (cKO) mice

proliferating myoblasts even with longer exposure time (Fig. 1b). According to the data sheet for the antibody and BLAST analysis of the provided epitope, the antibody could detect C/EBP $\alpha$ and C/EBPE. However, the molecular weight of the observed band does not overlap with $\mathrm{C} / \mathrm{EBP} \alpha$ (42 and $30 \mathrm{kDa}$ ) or C/EBPe isoforms (32, 27 and $14 \mathrm{kDa})$. To determine if the $23 \mathrm{kDa}$ band represented a novel C/EBP $\beta$ isoform, we examined the expression of this band in myoblasts overexpressing $\mathrm{C} /$ $E B P \beta$ (Fig. 1c). Over the course of differentiation, the band was only detected in empty vector control cells at $72 \mathrm{~h}$ of differentiation, while it remained undetectable in cells overexpressing C/EBP $\beta$ (Fig. 1c). We next examined the expression of this band in primary myoblasts isolated from a conditional knockout mouse (cKO) in which Cebpb is excised in satellite cells. Satellite cells were cultured in growth medium for $48 \mathrm{~h}$ and switched to differentiation medium for $48 \mathrm{~h}$ (the time course for differentiation of primary myoblasts is shorter than in $\mathrm{C} 2 \mathrm{C} 12$ cells). Knockout efficiency was confirmed by western blot (Fig. 1d) and C/EBP $\beta$-LAP expression in WT cells was downregulated with differentiation as previously reported $[9,10]$ (Fig. 1d). Interestingly, the $23 \mathrm{kDa}$ band was detected in differentiating WT and cKO myoblasts ruling out the possibility that this band is an isoform of C/EBP $\beta$ (Fig. 1d). Since C/EBP $\beta$ is an inhibitor of myogenesis $[9,10]$, the detection of the $23 \mathrm{kDa}$ band correlates with myogenic differentiation (detected only in differentiating myoblasts) and not with $\mathrm{C} / \mathrm{EBP} \beta$ expression (Fig. 1c, d).

\section{Anti-C/EBP $\beta$ detects MYL4 in differentiating myoblasts}

To identify the protein causing the $23 \mathrm{kDa}$ band in differentiating myoblasts, we performed an immunoprecipitation (IP) of whole cell extracts from $\mathrm{C} 2 \mathrm{C} 12$ myoblasts differentiated for three days using the anti-C/EBP $\beta$ antibody or non-specific IgG. The $23 \mathrm{kDa}$ band was successfully precipitated using the anti-C/EBP $\beta$ antibody but not by the control IgG as detected by silver staining (Fig. 2a, red box). Western blot analysis of the input and the $\mathrm{C} /$ EBP $\beta$-IP sample confirmed the pull down of the $23 \mathrm{kDa}$ band, and its absence in the control IP lane (Fig. 2b). The excised $23 \mathrm{kDa}$ band was analyzed by mass spectrometry, which identified 16 mouse proteins with molecular weights between 19 and $23 \mathrm{kDa}$ (Fig. 2c). Based on the spectrum counts, myosin light chain proteins (MYL4, MYL1/3 and MYL12b) were detected at higher levels than others. Similarly, myosin light chain proteins were more highly ranked based on the percentage of amino acids detected by the spectrum. Myosin light chain 4 was detected with 11 exclusive unique peptides, 13 exclusive unique spectra and 72 total spectra with $66 \%$ coverage (Fig. 2c). Myosin light chain 1/3 skeletal muscle isoform (MYL1) was detected with 11 unique peptides, 19 unique 


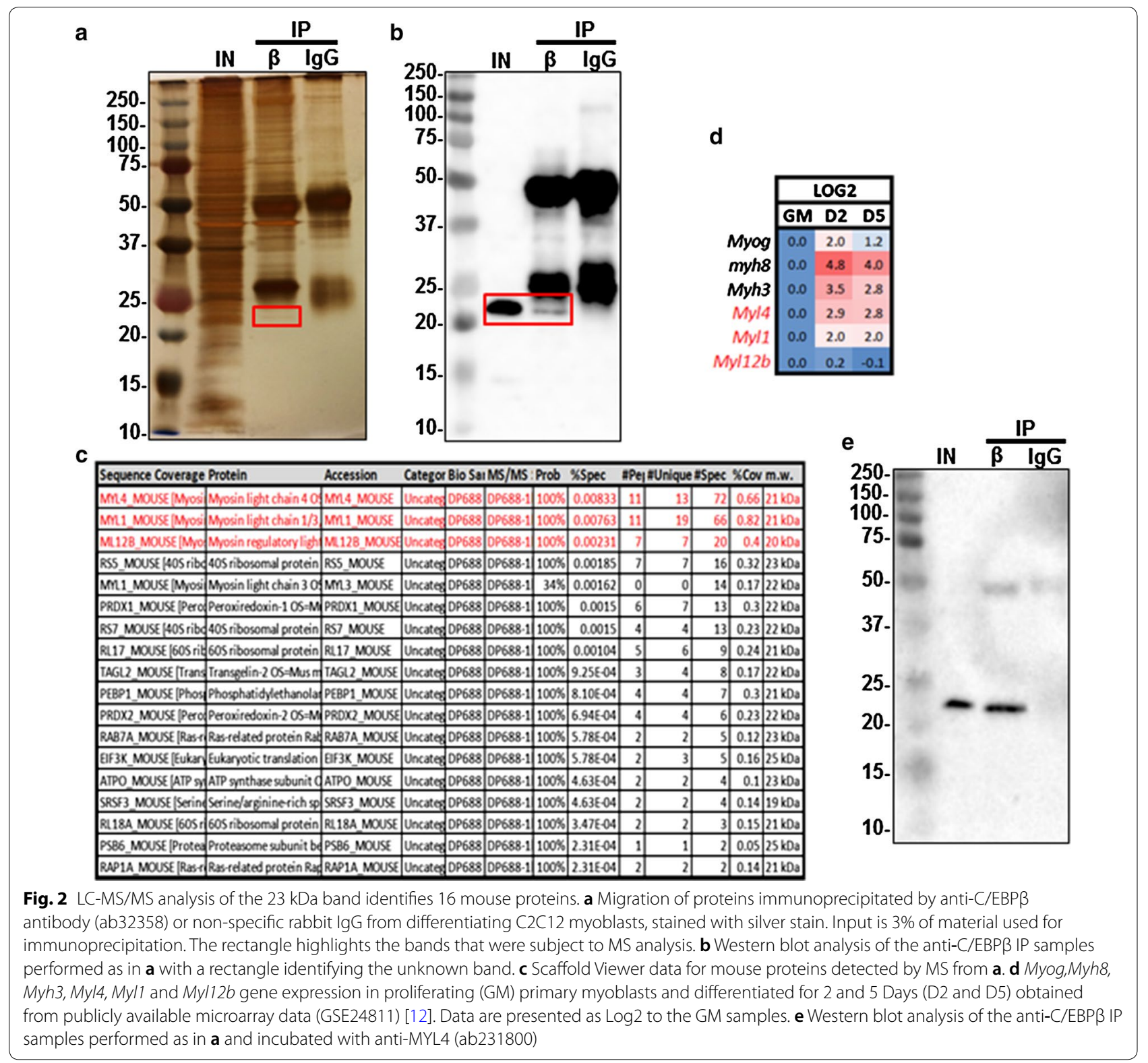

spectra, 66 total spectra and $82 \%$ coverage. MYL12b was also identified with 7 unique peptides and $40 \%$ sequence coverage. We used publicly available microarray data from proliferating (GM) and differentiated myoblasts (GSE24811) [12] to determine the expression pattern of the myosin light chain genes. In parallel with myogenin and myosin heavy chain 8 and 3 (markers of terminal differentiation), Myl4 and Myll were upregulated with myogenic differentiation (Fig. 2d). Myl12b gene expression remained stable with differentiation (Fig. 2d).

To confirm the identity of the band detected with the anti-C/EBP $\beta$ antibody, we incubated the membrane from Fig. 2b with antibody against MYL4, confirming the detection of MYL4 protein in the C/EBP $\beta$-IP sample at a similar level to the input (Fig. 2e). Furthermore, a western blot comparing extracts from undifferentiated myoblasts (GM), differentiated myotubes (D3), extracts from HEK293 cells (human) and recombinant myosin light chain proteins was performed (Fig. 3). The anti-C/EBP $\beta$ antibody failed to detect recombinant MYL12B, but did recognize recombinant MYL4 protein, as well as a band in HEK293 cells (Fig. 3). Interestingly, while HEK293 cells are not thought to express MYL4, human MYL4 is known to be slightly larger than the mouse protein. Loading of recombinant proteins was verified using an antibody that detects multiple isoforms of MYL (MYL1, 


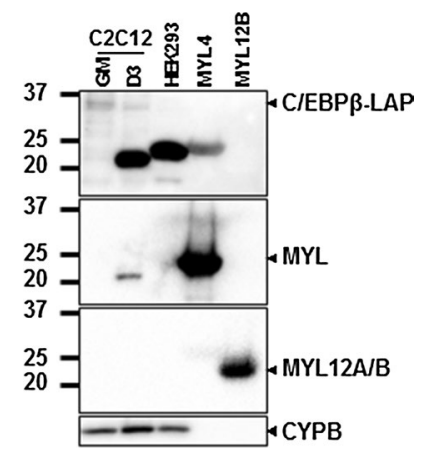

Fig. 3 Anti-C/EBP $\beta$ antibody (ab32358) detects MYL4 in differentiating myoblasts. Western blot of extracts from proliferating myoblasts (GM), 3-day differentiated myoblasts (D3) and HEK293 cells compared to human recombinant MYL4 (ab115722) and human recombinant MYL12B (ab128438) probed with anti-C/EBPß (ab32358), anti-MYL (sc-365243) and anti-MYL12A/B (sc-376606). Cyclophilin B is used as loading control

MYL3, MYL4 and MYL6), which also detected a band in differentiated $\mathrm{C} 2 \mathrm{C} 12$ extracts but not HEK293 cells, or against MYL12A/B. The anti-C/EBP $\beta$ antibody failed to recognize recombinant MYL1 (data not shown). Thus, these findings suggest that the previously unidentified band detected by anti-C/EBP $\beta$ in differentiating myoblasts corresponds to MYL4.

\section{Discussion}

The advancement of scientific knowledge relies on the capacity to build on shared knowledge. At the heart of this is the choice of tools, including antibodies that are validated both by suppliers and researchers. Herein, we describe the validation of an anti-C/EBP $\beta$ antibody that is reported to detect all three $\mathrm{C} / \mathrm{EBP} \beta$ protein isoforms, but also shows specificity for MYL4, which is present in differentiating myoblasts, myotubes and myofibers, and numerous other cell lines, including commonly used cancer cell lines and cardiac muscle. Because the molecular weight of MYL4 is close to that of the C/EBP $\beta$-LIP isoform, in tissues and cells that also express MYL4, of which many do, caution must be used when identifying the LIP isoform, and researchers should use extreme caution when using this antibody to detect C/EBP $\beta$ by immunofluorescence.

Interestingly, the anti-C/EBP $\beta$ antibody also detected a band in HEK293 cells, which was not detected by antibodies that recognize MYL1/3/4/6 proteins. While HEK293 cells do not express these proteins, there is high sequence conservation between MYL family genes. As such, the band detected in the HEK293 cells using the anti-C/EBP $\beta$ antibody may represent cross-reactivity with a non-muscle human isoform of MYL that has sequence identity with mouse MYL4.

The anti-C/EBP $\beta$ antibody is described as a monoclonal antibody. However, the presence of at least two specificities in the absence of similarity between the epitope and the MYL4 sequence suggests that the hybridoma used to produce this antibody is the most likely source of the contamination, with the presence of at least 2 clones of antibody-producing cells, one for anti-C/EBP $\beta$ antibody and one that produces the anti-MYL4 antibody.

\section{Limitations}

In our mass spectrometry experiment, we did not isolate and analyze a gel slice corresponding to the migration of the C/EBP $\beta$-LAP isoform, which would have further confirmed the dual specificity for the antibody.

\section{Abbreviations}

C/EBP: CCAAT/Enhancer Binding Protein; MYL: myosin light chain; LAP: liverenriched activating protein; LIP: liver-enriched inhibitory protein; DMEM: dulbecco's modified eagle medium; FBS: fetal bovine serum; HS: horse serum; GM: growth medium; DM: differentiation medium; SDS-PAGE: sodium dodecyl sulphate-polyacrylamide gel electrophoresis; PVDF: polyvinylidene difluoride; LC-MS/MS: liquid chromatography with mass spectrometry; HPLC: high performance liquid chromatography.

\section{Acknowledgements}

The Pax7-CreER mouse was kindly provided by Dr. Charles Keller at Oregon Health \& Science University (Portland, OR), and the Cebpb f//fl mouse was a kind gift from Dr. Esta Sterneck at the Center for Cancer Research at the National Institutes of Health.

\section{Authors' contributions}

HA contributed to the conception and design, collection, assembly, analysis and interpretation of data, the manuscript writing and final approval of the manuscript. NWB contributed to the conception and design, analysis and interpretation of data, financial support, the manuscript writing, and the final approval of manuscript. All authors read and approved the final manuscript.

\section{Funding}

This work was supported by grant from the Canadian Institutes of Health Research (CIHR) (Grant number 148613) to NWB. HA is supported by a graduate scholarship from King Saud University, Saudi Arabia. The funders had no role in study design, data collection, analysis, interpretation of data, no in writing the manuscript.

\section{Availability of data and materials}

All data generated or analyzed during this study are included in this published article.

\section{Ethics approval and consent to participate}

All animal experimentation was approved by the University of Ottawa Animal Care Committee (protocol \#2166) and conformed to the guidelines set out by the Canadian Council on Animal Care.

\section{Consent for publication}

Not applicable.

\section{Competing interests}

The authors declare that they have no competing interests.

\section{Author details}

${ }^{1}$ Graduate Program in Cellular and Molecular Medicine, Faculty of Medicine, University of Ottawa, 451 Smyth Road, Rm 3106, K1H 8M5, Ottawa, ON, 
Canada. ${ }^{2}$ Department of Cellular and Molecular Medicine, Faculty of Medicine, University of Ottawa, 451 Smyth Road, Rm 2539, K1H 8M5, Ottawa, ON Canada.

Received: 18 July 2019 Accepted: 18 October 2019

Published online: 31 October 2019

\section{References}

1. Köhler G, Milstein C. Continuous cultures of fused cells secreting antibody of predefined specificity. Nature. 1975;256:495-7.

2. Bradbury ARM, et al. When monoclonal antibodies are not monospecific: hybridomas frequently express additional functional variable regions. MAbs. 2018;10:539-46.

3. Tsukada J, Yoshida Y, Kominato Y, Auron PE. The CCAAT/enhancer (C/EBP) family of basic-leucine zipper (bZIP) transcription factors is a multifaceted highly-regulated system for gene regulation. Cytokine. 2011;54:6-19.

4. Cao Z, Ume R, McKnight S. Regulated expression of three C/EBP isoforms during adipose conversion of 3T3-L1 cells. Genes Dev. 1991;5:1538-52.

5. Descombes P, Schibler U. A liver-enriched transcriptional activator protein, LAP, and a transcriptional inhibitory protein, LIP, are translated from the same mRNA. Cell. 1991;67:569-79.

6. Calkhoven CF, Muller C, Leutz A. Translational control of C/EBPalpha and C/EBPbeta isoform expression. Genes Dev. 2000;14:1920-32.
7. Mauro A. Satellite cell of skeletal muscle fibers. J Biophys Biochem Cytol. 1961;9:493-5.

8. Bischoff R. Regeneration of single skeletal muscle fibers in vitro. Anat Rec 1975;182:215-35.

9. Marchildon F, et al. CCAAT/enhancer binding protein beta is expressed in satellite cells and controls myogenesis. Stem Cells. 2012;30:2619-30.

10. AlSudais H, Lala-Tabbert N, Wiper-Bergeron N. CCAAT/Enhancer Binding Protein $\beta$ inhibits myogenic differentiation via ID3. Sci Rep. 2018;8:16613.

11. Fu D, Lala-Tabbert N, Lee H, Wiper-Bergeron N. Mdm2 promotes myogenesis through the ubiquitination and degradation of CCAAT/Enhancerbinding protein $\beta$. J Biol Chem. 2015;290:10200-7.

12. Soleimani VD, et al. Snail regulates myod binding-site occupancy to direct enhancer switching and differentiation-specific transcription in myogenesis. Mol Cell. 2012;47:457-68.

13. Shevchenko A, Tomas H, Havli J, Olsen JV, Mann M. In-gel digestion for mass spectrometric characterization of proteins and proteomes. Nat Protoc. 2006;1:2856-60

\section{Publisher's Note}

Springer Nature remains neutral with regard to jurisdictional claims in published maps and institutional affiliations.
Ready to submit your research? Choose BMC and benefit from:

- fast, convenient online submission

- thorough peer review by experienced researchers in your field

- rapid publication on acceptance

- support for research data, including large and complex data types

- gold Open Access which fosters wider collaboration and increased citations

- maximum visibility for your research: over $100 \mathrm{M}$ website views per year

At $\mathrm{BMC}$, research is always in progress.

Learn more biomedcentral.com/submissions 